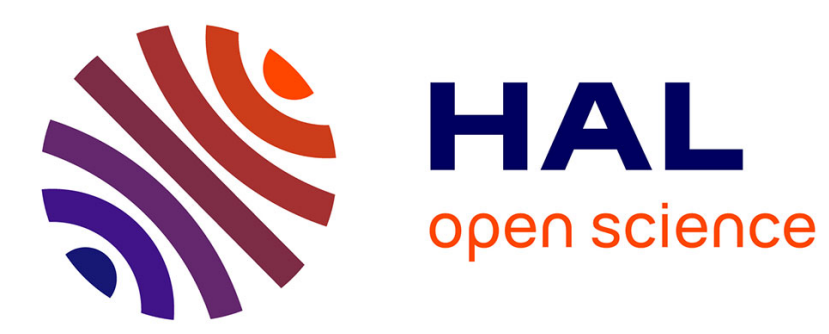

\title{
EBIC and conductance measurements in poly- and bicrystalline silicon
}

\author{
A. Bary, B. Mercey, G. Poullain, J.L. Chermant, G. Nouet
}

\section{To cite this version:}

A. Bary, B. Mercey, G. Poullain, J.L. Chermant, G. Nouet. EBIC and conductance measurements in poly- and bicrystalline silicon. Revue de Physique Appliquée, 1987, 22 (7), pp.597-601. 10.1051/rphysap:01987002207059700 . jpa-00245582

\section{HAL Id: jpa-00245582 https://hal.science/jpa-00245582}

Submitted on 1 Jan 1987

HAL is a multi-disciplinary open access archive for the deposit and dissemination of scientific research documents, whether they are published or not. The documents may come from teaching and research institutions in France or abroad, or from public or private research centers.
L'archive ouverte pluridisciplinaire HAL, est destinée au dépôt et à la diffusion de documents scientifiques de niveau recherche, publiés ou non, émanant des établissements d'enseignement et de recherche français ou étrangers, des laboratoires publics ou privés. 


\title{
EBIC and conductance measurements in poly- and bicrystalline silicon
}

\author{
A. Bary, B. Mercey, G. Poullain, J. L. Chermant, G. Nouet \\ Laboratoire de Cristallographie, Chimie et Physique des Solides, U.A. CNRS 251, Institut des Sciences de la \\ Matière et du Rayonnement, Université de Caen, 14032 Caen Cedex, France
}

(Reçu le 20 novembre 1986, révisé le 17 mars 1987, accepté le 19 mars 1987)

\begin{abstract}
Résumé. - L'analyse de la recombinaison des porteurs minoritaires par E.B.I.C. sur des cellules solaires en silicium polycristallin montre que seule la macle miroir $\Sigma 3$ de plan $\{111\}$, sans déviation à la coïncidence exacte et sans décoration, ne montre aucune activité électrique. L'influence de la ségrégation est prise en considération pour expliquer les différents comportements de la macle miroir $\Sigma 9$ de plan $\{221\}$. Deux joints présentant des écarts à la coïncidence sont faiblement actif $(\Sigma 3)$ ou fortement actif ( $\Sigma 5$ ). Des mesures de conductance sont réalisées sur des bicristaux $(\Sigma 9,13,25,27)$, à l'état brut de tirage et après différents traitements thermiques.
\end{abstract}

\begin{abstract}
Grain boundaries cut from polycrystalline solar cells were investigated by E.B.I.C. mode. Only the exact mirror twin $\Sigma 3$ shows no electrical activity. In order to explain the two types of behaviour of the twin $\Sigma 9$, the segregation of impurities must be taken into account. The other boundary planes analyzed are either symmetric with a deviation from the exact coincidence $(\Sigma 3,5)$ or asymmetric $(\Sigma 3,9,25,27)$. The conductance of several bicrystals $(\Sigma 9,13,25,27)$ was measured on as-grown bicrystals and after annealing.
\end{abstract}

\section{Introduction.}

In the last ten years, one of the most significant point in the photovoltaic field has concerned the study of dislocations, low-angle and high-angle boundaries in polycrystalline silicon. The structural investigations by H.R.E.M., based on the concept of the coincidence site lattice, have shown that the structures of coincidence grain boundaries are described as atomic rings. These rings or structural units can contain deformed bonds and dangling bonds. Consecutively, these bonds were identified as potential trapping sites in grain boundaries and associated to the interface states in the bandgap [1]. The electrostatic charges, localized in or close to the boundary plane are responsible for the potential barriers which are detected, for example, by electron beam induced current or measurement of conductance.

Materials always contain impurities. Thus, it is of prime importance to know how these impurities are able to modify the electrical properties of a coincidence grain boundary. In the first part of that paper, E.B.I.C. analysis on specimens cut from solar cells are reported [2]. The second part deals with the measurements of the conductance across the bound- ary plane for well-defined bicrystals specially grown [3]. The study of the transport of minority or majority carriers provides information concerning the contribution of the atomic structure and the contribution of the atoms segregated.

\section{Experimental methods.}

The specimens analysed were p-type boron silicon bicrystals. In the case of E.B.I.C. analysis, the bicrystals were taken in polycrystalline solar cells. The as-grown polycrystalline silicon was supplied by Wacker and the junction was diffused at $850{ }^{\circ} \mathrm{C}$ for $30 \mathrm{~min}$ in a $\mathrm{POCl}_{3}$ atmosphere by Photowatt Int... These specimens were examined by E.B.I.C. mode at an accelerating voltage of $30 \mathrm{kV}$ to investigate the minority carrier recombination in the vicinity of the grain boundary.

In order to link this recombination to the geometrical structure of the grain boundaries, these specimens were cut, thinned and analysed by transmission electron microscopy. The deviation from the twin orientation between both adjacent grains was calculated using the Kikuchi maps. It consists of the measurement of the shift of Kikuchi map centres in 
the vicinity of the boundary plane. The great advantage of this method is the accurate location of the supplementary rotation axis. Consequently, the deviation from the coincidence is defined by a tilt, twist or mixed character [2].

The measurements of conductance were carried out on bicrystals. Some of them were specially grown $(\Sigma 9,13,25)$, by Ceng. Leti [4] and another cut from a polycrystalline wafer provided by Photowatt Int. ( $\Sigma 27)$. The conductance of each specimen was measured by the four probe method in the temperature range $100-300 \mathrm{~K}$. The boundary plane is normal to the imposed current. For every experiment, the conductance of one grain and that of the boundary plane were measured. The measurements were performed on as-grown bicrystals and after a $\left(850^{\circ} \mathrm{C}-30 \mathrm{~min}\right)$ heat treatment either in a $\mathrm{POCl}_{3}$ atmosphere or in vacuum.

The orientations $\Sigma 13$ and 25 correspond to a rotation about a $\langle 100\rangle$ axis whereas the orientations $\Sigma 9$ and 27 correspond to a rotation about a $\langle 110\rangle$ axis. The boundary planes are symmetric for the three orientations $\Sigma 9,13$ and $25:\{221\}$, $\{510\}$ and $\{710\}$ respectively. The boundary plane of the orientation $\Sigma 27$ is asymmetric : $\{111\}$ parallel to $\{11111\}$. The coincidence orientations are exact except the orientation $\Sigma 25$. A dislocation network lying in the boundary plane accommodates a $0.5^{\circ}$ tilt deviation.

\section{Analysis of coincidence grain boundaries in E.B.I.C. mode.}

The qualitative analysis of grain boundaries enables us to classify them depending on whether their electrical activity is strong or weak. The aim of this classification is to show how the atomic structure and the segregated impurities are able to modify the electrical activity of the coincidence grain boundaries.

3.1 IDEAL SYMMETRIC STRUCTURES. - Two types of grain boundaries with $\langle 110\rangle$ rotation axis were studied : $\Sigma 3$ and 9 twin orientations. The boundary planes are the $\{111\}$ and $\{221\}$ symmetric planes respectively. The atomic structures of these two common twins are now well established. The ideal orientation $\Sigma 3$ or mirror twin is composed of an array of a unique unit. The only modification between a perfect monocrystal and the $\Sigma 3$ orientation is the shape of the structural unit: a chair shaped six-atom ring for the perfect monocrystal and a boat shaped ring for the $\Sigma \mathbf{3}$ twin mirror [5]. The ideal orientation $\Sigma 9$, a mirror twin as well, is described by high resolution electron microscopy observations with a 5-7 atom ring. This unit is deformed and some angles and lengths of the bonds are highly distorted $[5,6]$.

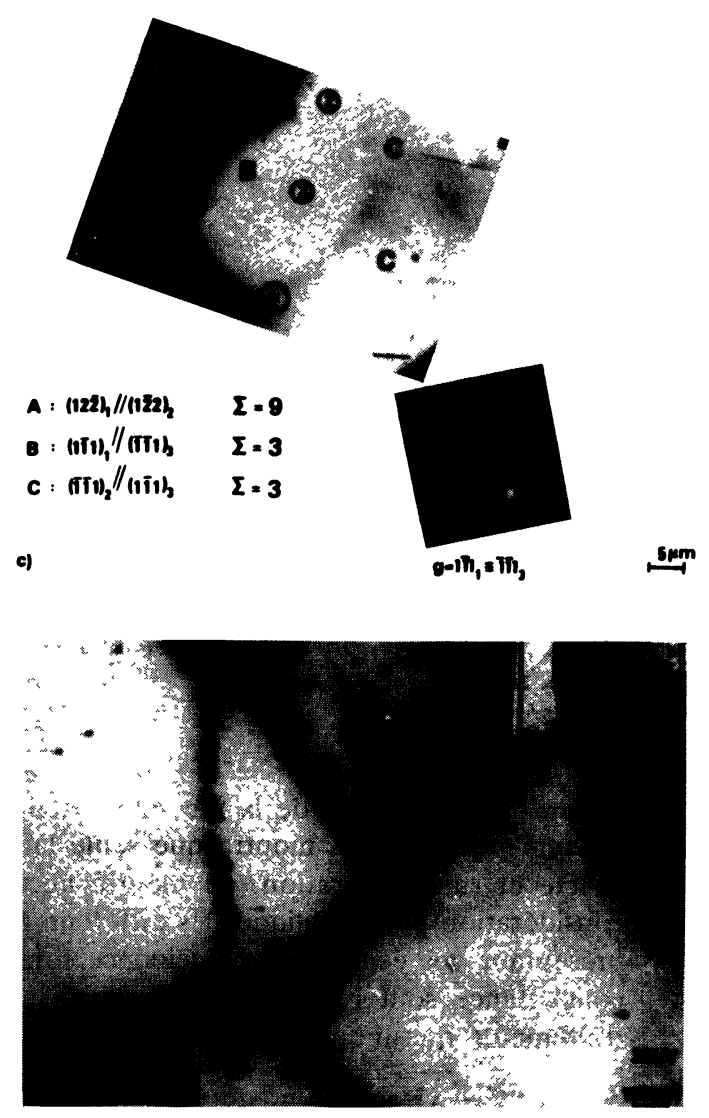

Fig. 1. - E.B.I.C. image of a twinned structure $\Sigma 3$ and $\Sigma 9$ :

a) E.B.I.C. image showing a dot contrast. b) Optical image. c) Details of the twinned structure by T.E.M.

The $\Sigma 3$ ideal twin can have never been imaged by E.B.I.C. mode and thus no recombination of the minority carriers can be attributed to this type of boundary [7]. Generally, similar observations are obtained with the second order twin $\Sigma 9$, but sometimes this orientation displays a very strong contrast on the E.B.I.C. image although no precipitate was detected by T.E.M. (Fig. 1) [2]. This recombination of the minority carriers cannot be explained by the only geometric structure of such an interface which contains no dangling bonds. However, it has been shown that these highly deformed bonds are attractive sites for the segregation of impurities. The configuration of the 5-7 atom rings required to construct the dislocation cores of this interface is closely related to the core of the Lomer dislocation. The segregation of oxygen often occurs on this type of dislocation and seems to be essential to stabilize these atomic structures [8]. A tentative of explanation of these different behaviours is the nature of interfaces either internal such as growth, mechanical twins, or grain boundaries. A most detailed study will be published elsewhere [9]. Thus, we can draw the following conclusion from these different obser- 
vations : the tetrahedrally coordinated sites of the ideal symmetric twin $\Sigma 9$ can be effective sites of segregation although the atomic reconstruction of the symmetric boundary plane $\{221\}$ requires no dangling bonds.

3.2 GRAIN BOUNDARIES DEVIATING FROM THE EXACT COINCIDENCE. - The twin orientations observed in polycrystalline silicon are not always exact and the deviation from this exact coincidence is accommodated with particular dislocation networks : the intrinsic secondary dislocations [10]. If the deviation is not too important, the dislocation networks can be analysed by T.E.M. Two near-coincidence orientations were studied : a grain boundary $\Sigma 3$, boundary plane $\{111\}$, characterized with a deviation of $0.13^{\circ}$ and an orientation $\Sigma 5$, boundary plane $\{310\}$, with a deviation of $4.1^{\circ}$.

The detailed analysis of the orientation $\Sigma 3$ has shown a periodic network of Frank dislocations with a $1 / 3\langle 111\rangle$ Burgers vector. The supplementary rotation axis is lying in the boundary plane and the deviation from the exact coincidence is purely tilt [2]. It has been demonstrated, by H.R.E.M. study, that the core of this type of dislocation is recon-

อ)
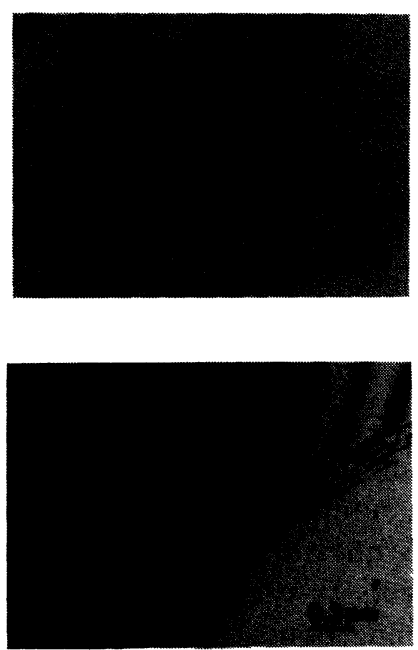

b)

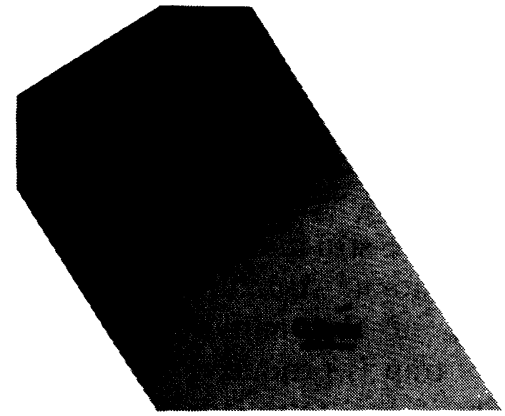

Fig. 2. - Twin $\Sigma 3$ deviating from the coincidence :

a) E.B.I.C. image showing two slight contrast $A_{1}$ and $A_{2}$. b) Dislocation networks with Burgers vector $1 / 3\langle 111\rangle$ in the boundary planes $\{111\} A_{1}$ and $A_{2}$. REVUE DE PHYSIQUE APPLIQUÉE. - T. 22, N 7, JUILLET 1987 structed with a 5-7 atom ring [5, 6]. In our case, the twin $\Sigma 3$ with the deviation of $0.13^{\circ}$ can be imaged by E.B.I.C. mode and shows a rather slight contrast (Fig. 2). As the core of the Frank dislocation is disturbed, one can assume that they could also act as sinks for the internal impurities.

In the case of the orientation $\Sigma 5$, a network of dislocations is also lying in the boundary plane $\{310\}$. This deviation is large and the Burgers vectors were not determined. However the good periodicity of the dislocations emphasizes the deviation from the coincidence. The contrast observed, by E.B.I.C. mode, is very strong (Fig. 3). This twin is described by a $\langle 100\rangle$ rotation axis but the corresponding structural units have not yet been resolved unambiguously, some deformed rings with 3 and 5 atoms were proposed [5].

Once more the electrical activity could be attributed to the segregation at the more deformed sites of the atomic rings.

3.3 ASYMMETRIC COINCIDENCE GRAIN BOUNDARY. - In both cases analysed, the coincidence orienta-

a)
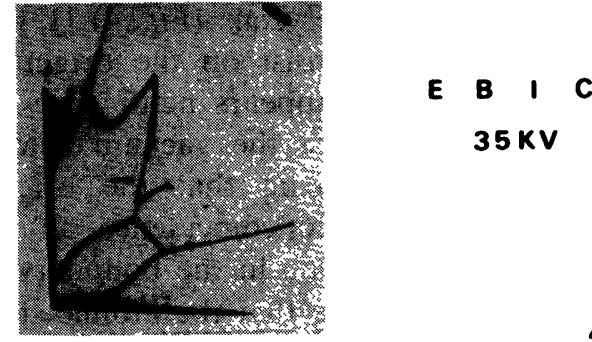
$35 \mathrm{KV}$

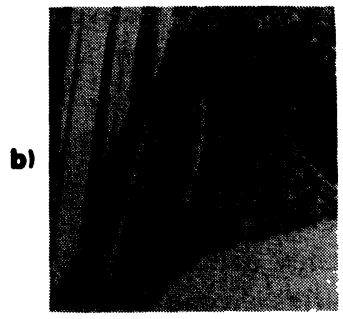

OPTIQUE
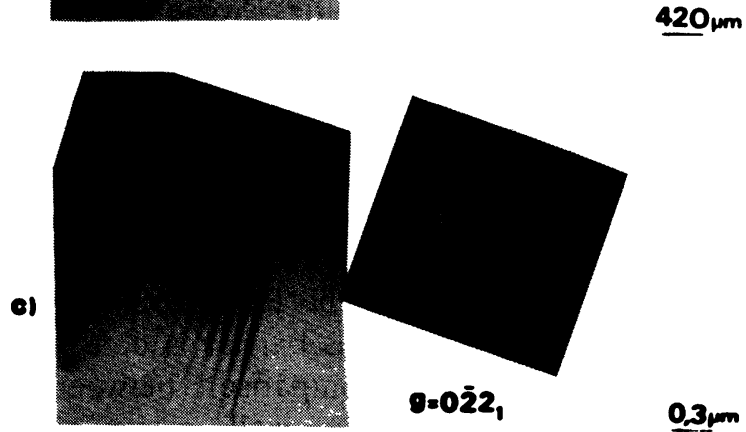

0,3m

Fig. 3. - Twin $\Sigma 5$ deviating from the exact coincidence : a) E.B.I.C. image showing the part of the boundary plane analysed by T.E.M. b) Optical micrograph of the some area. c) Network of intrinsic secondary dislocations lying in the boundary plane $\{310\}$. 
tions are exact, no deviation was determined. However, the boundary plane is no more a mirror plane. For the orientation $\Sigma 9$, the $\{111\}$ planes are parallel to the $\{115\}$ planes and for the orientation $\Sigma 27$, the parallel planes are $\{111\}$ and $\{11111\}$. The atomic structures of the asymmetric grain boundaries are hardly known [6]. To same extent, it is likely that a greater number of structural units is really necessary to construct this type of interface. Moreover, these boundary planes often contain a lot of defects such as dislocations and precipitates. Therefore, the strong electrical activity of these interfaces seems to be more obvious.

\section{Conductance of coincidence grain boundaries.}

The as-grown bicrystals $\Sigma 9,13,25$ do not show any modification of the conductance. The plots $G=$ $f(1 / T)$ are similar for the grains and for the boundaries, thus the transport of the majority carriers is unchanged $[11,12]$. After the $\mathrm{POCl}_{3}$ treatment, the plot of the orientation $\Sigma 13$ is very weakly modified whereas the one of the orientation $\Sigma 25$ exhibits a maximum at $253^{\circ}$. A potential barrier equal to $0.11 \mathrm{eV}$ is calculated. Unlike this treatment, the equivalent vacuum thermal treatment retains the plots of the as-grown bicrystals (Fig. 4) [13]. From these results, we may insist on the origin of the potential barrier which appears neither on the asgrown bicrystals nor after the vacuum heat treatment. It is worth noticing that the orientation $\Sigma 25$ deviates from the exact coincidence, an intrinsic dislocation network is lying in the boundary plane. Therefore we can assume that the atomic structure of the grain boundary in the as-grown bicrystal is not disturbed enough to create electrically active trapping sites. In the same way, the vacuum thermal treatment is no more efficient. Conversely, a potential barrier only occurs after the $\mathrm{POCl}_{3}$ treatment. The different behaviours of these three bicrystals specially grown prove that their atomic structure are not intrinsically active. But, they are not equivalent against the diffusion of impurities. Some of them are weaker than others. It is very likely that the increasing complexity of the reconstruction in the boundary plane offers great ability for segregation.

The behaviour of the orientation $\Sigma 27$ differs somewhat from others because a $0.02 \mathrm{~V}$ potential barrier occurs in the as-grown condition at $185 \mathrm{~K}$. This barrier increases after the $\mathrm{POCl}_{3}$ treatment to attain $0.18 \mathrm{eV}$, moreover this barrier is detected at room temperature. The comparison between the behaviour of the bicrystals specially grown and of the «industrial bicrystal» is very difficult. The growth conditions and the crystallography of the boundary planes are quite different, the asymmetric interface of the orientation $\Sigma 27$ has not yet been resolved. Its artificial reconstruction with a model of
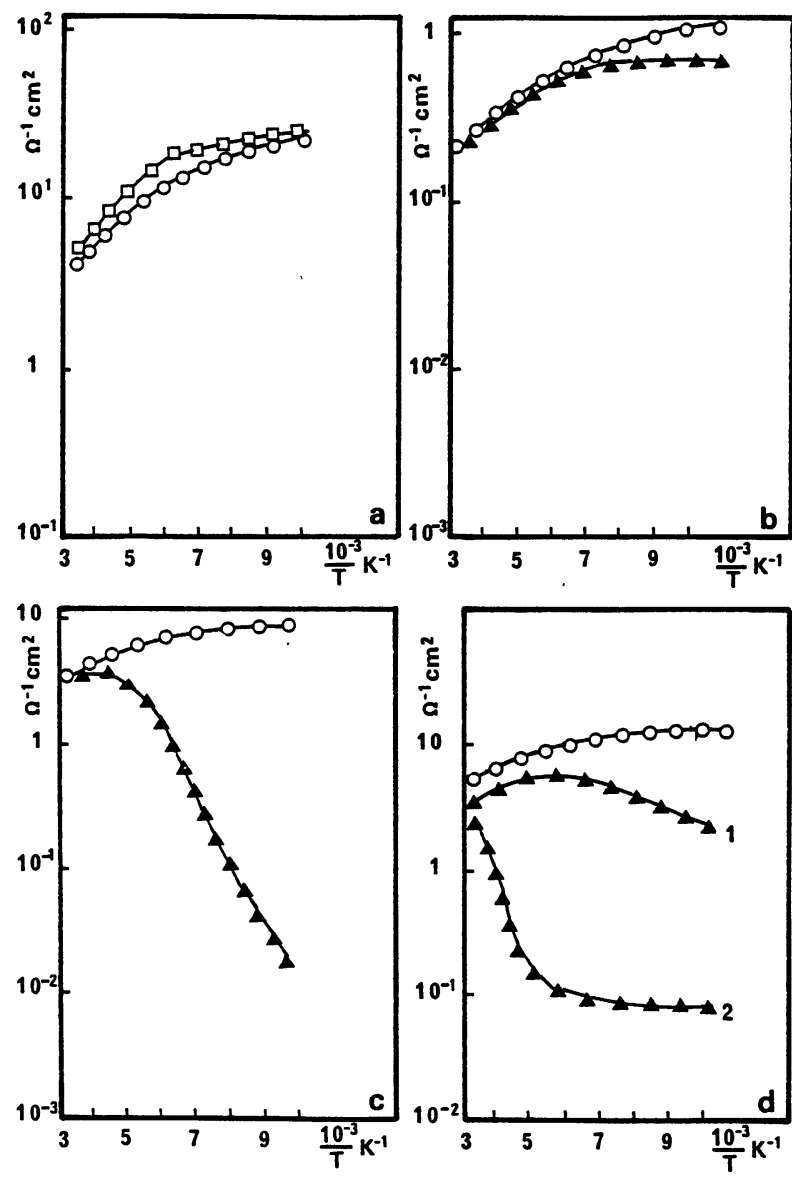

Fig. 4. - Conductance of bicrystals :

a) $\Sigma 9$ twin : $\bigcirc$ grains, $\square$ boundary, plots obtained on asgrown bicrystal and after $\mathrm{POCl}_{3}$ and vacuum treatment. b) $\Sigma 13$ twin : $O$ grains and boundary for the as-grown and vacuum treatment, $\Delta: \mathrm{POCl}_{3}$ treatment. c) $\Sigma 25$ twin : 0 grains and boundary for the as-grown and vacuum treatment, $\Delta: \mathrm{POCl}_{3}$ treatment. d) $\Sigma 27$ twin : $\mathrm{O}$ grains, $\boldsymbol{\Delta}_{1}$ boundary : as-grown, $\boldsymbol{\Delta}_{2}$ : boundary : $\mathbf{P O C l}_{3}$.

pikes and balls requires some dangling bonds [3]. Even if this assumption is justified, no answer can be given to the question: the recombination of the charged carriers is due to crystallographic defects such as dangling bonds or to segregated atoms.

\section{Conclusion.}

The symmetric orientations studied $\Sigma 9,13,25$ do not exhibit dangling bonds and the mobility of the majority carriers is not modified by these reconstructed atomic structures. The intrinsic reconstruction of the atomic structure can be affected by the segregation of the native oxygen. However no electrically trap is produced with the disturbance of the bonds if the tetrahedrally coordinance is retained. These atomic configurations are even stable after some heat treatments. Only, the $\mathrm{POCl}_{3}$ treatment gives rise to energy levels in the band gap which are detected by the variation of the conduc- 
tance. But it is worth noticing that the atomic structure of the orientation $\Sigma 25$ includes particular structural units. Therefore one can assume that some of these structural units are less stable than others. This result enables the assumption about the impurity segregation in the $\Sigma 3$ and 5 grain boundaries which deviate from the coincidence to be verified. However, even an exact coincidence grain boundary, $\Sigma 9$, was imaged by E.B.I.C. mode with a regular array of identical structural units.

The action of the annealing atmosphere is not always obvious and additional experiments will be necessary to enhance our understanding of the relation between thermal treatment and recombination.

\section{Acknowledgments.}

This work was supported by CNRS (PIRSEM 39-8427, AIP $n^{\circ} 2018$ ), AFME and EDF ( $\left.{ }^{\circ} 1 B 5988\right)$. The authors thank Photowatt Int. for providing Polyx wafers and Mr Aubert (LETI-CEN Grenoble) for silicon bicrystals specially grown.

\section{References}

[1] Grovenor, C. R. M., J. Phys. C 18 (1985) 4079.

[2] BARY, A., Thèse de Doctorat de $3^{\mathrm{e}}$ cycle, Caen (1984).

[3] Poullain, G., Thèse de Doctorat, Paris (1985).

[4] Aubert, J. J., Bacmann, J. J. This issue.

[5] Bourret, A., J. Physique Colloque 46 (1985) 27.

[6] Bourret, A., D’Anterroches, C., Penisson, J. M., J. Physique Colloque 43 (1982) 83.

[7] Bary, A., Chermant, J. L., Nouet, G., Physical Chemistry of Solid State Paris (1984) (Ed. by Lacombe P., Elsevier, Amsterdam) 1984, 319.

[8] Bourret, A., Desseaux, J., Renault, T., Phil. Mag. A 45 (1982) 1.

[9] BARY, A., Nouet, G. (to be published).
[10] Nouet, G., BACMAnN, J. J., Les joints de grains dans les matériaux, Ecole d'Eté de Métallurgie Physique, Carry-le-Rouet, Septembre 1984. (Les Editions de Physique, Paris) (1984) 43.

[11] Poullain, G., Mercey, B., Nouet, G., Poly-micro-crystalline and amorphous semiconductors MRS-E, juin 1984. Strasbourg (Ed. by Pinard P., Kalbitzer S. Les Editions de Physique, Paris) 1984, 359.

[12] Poullain, G., Bary, A., Mercey, B., Lay, P., Chermant, J. L., Nouet, G., Grain Boundary Structure and Related Phenomena, Proceedings of JIMIS-4 (1986) Suppl. to Trans. Jap. Inst. Metals 27 (1986) 1069.

[13] Poullain, G., Mercey, B., Nouet, G., J. Appl. Phys. 61 (1987) 1547. 